\title{
Descartes, corpuscles and reductionism: mechanism and systems in Descartes's physiology
}

Barnaby R. Hutchins

\begin{abstract}
I argue that Descartes explains physiology in terms of whole systems, and not in terms of the size, shape and motion of tiny corpuscles (corpuscular mechanics). It is a standard, entrenched view that Descartes's proper means of explanation in the natural world is through strict reduction to corpuscular mechanics. This view is bolstered by a handful of corpuscularmechanical explanations in Descartes's physics, which have been taken to be representative of his treatment of all natural phenomena. However, Descartes's explanations of the 'principal parts' of physiology do not follow the corpuscular-mechanical pattern. Des Chene (200I) has identified systems in Descartes's account of physiology, but takes them ultimately to reduce down to the corpuscle level. I argue that they do not. Rather, Descartes maintains entire systems, with components selected from multiple levels of organisation, in order to construct more complete explanations than corpuscular mechanics alone would allow.
\end{abstract}

Keywords: Descartes; mechanism; reductionism; systematicity

\section{Introduction}

This paper is a reconstruction of Descartes's approach to physiology in which his explanations of the principal operations of the body are understood in terms of systems. A systems reading of Descartes's physiology is at odds with the received view on explanation in Descartes's natural philosophy, which takes him to reduce all phenomena in the natural world to 'the size, shape, and motion of the tiny parts that make it up' (Garber 200Ic: II2). A systems explanation cannot be a reduction right down to this corpuscular mechanics, because it is the system itself that carries the explanatory weight, rather than its lowest-level components. 
Elsewhere in his natural philosophy, Descartes arguably does make use of explanations in terms of corpuscular mechanics (but see $\$ 3.3$ for discussion of whether even his physics is corpuscular mechanical). Most notably, the propagation and colour of light are reduced to, respectively, tendency to longitudinal motion and rotation of the very smallest pieces of matter. These explanations of light have come to be seen as archetypal for Descartes's treatment of natural phenomena. ${ }^{\mathrm{I}}$ Given his commitment to the unity of the sciences, it makes sense to presume that Descartes explains all aspects of the natural world, including physiology, in the same way, such that what goes for light also goes for the living body. ${ }^{2}$ Thus, Clarke tells us that 'Descartes's whole scientific project is one of imaginatively constructing descriptions of the motions of particles which might explain natural phenomena' (1982: 124); in a recent paper, Theurer asserts that Descartes's aim is 'to explain all of human physiology in terms of the principles of Cartesian physics. Ideally, all of this could be explained in terms of the properties of fundamental particles' (2OI3: 9I2-3). This position is echoed in both Hatfield I992 (340) and (in a more restricted context) Hatfield 2002 (635), while Fuchs (200I) sees Descartes's aim in physiology as being 'to explain vegetative-vital processes exclusively in terms of [the] lowest level' (I23), which involves reducing the 'vital heat' provided by the heart to nothing more than 'an exothermic reaction of particles' (II5). It is symptomatic of this approach that Smith (2006a: I4; 2006b: 88) sees Descartes's inability to account for embryogenesis specifically in terms of corpuscular mechanics as a 'failure'.

By contrast, Des Chene (200I) has convincingly shown that there is more to Descartes's treatment of physiology than corpuscles: there are systems too. Similarly, Brown (2OII) has argued that Descartes's account of embryogenesis consists of a 'whole matrix of interdependent

\footnotetext{
I The propagation of light tends to be the key example in scholarship on Descartes's use of analogy in natural philosophy. See, e.g., Clarke I982 (I22ff.), Galison I984; Manning 20I2. The account of colour is often used to exemplify Descartes's reductive method, since it is part of the conclusion of his only extended description of his own use of his method, given in Discourse 8 of the Meteors (see, e.g., Buchwald 2008, Clarke I982 (I73ff.), Garber 200Ia, Garber 200Ib, Georgescu and Giurgea 2012).
}

${ }^{2}$ Descartes's most significant statement of commitment to the unity of sciences is of course the simile of the tree of knowledge in the preface to the French edition of the Principles of Philosophy (AT IXB: 14-5; CSM I: I86). 
processes' (I2), which I suspect we may take to suggest something strongly systemic. ${ }^{3}$ As Des Chene puts it, for Descartes, 'the body is to be analysed into systems of mechanisms, and each mechanism into simpler mechanisms, until we arrive at mechanisms whose capacities can be understood in terms of the modes and derived properties of extended things' (200I: 154).

I take Des Chene's identification of systems of mechanisms seriously. However, Des Chene sees Descartes as moving away from systems, proceeding through a string of recursive reductions until reaching the level of corpuscular mechanics ('the modes and derived properties of extended things'). This is entirely consistent with Descartes's ontological commitments, but it is not, I want to argue, the approach that Descartes takes in accounting for the 'principal parts' (Passions a. 6) of the body. It is the reduction to the lowest level that I argue against here: instead of reduction to corpuscular mechanics, Descartes explains the operation of the body through whole systems. And the components of those systems exist at different levels. In other words, the systems remain systems; they do not get reduced away to corpuscles.

If my reading is correct, then what goes for light does not in fact go for the living body. If the explanations of light are taken to be archetypal of Cartesian explanation in natural philosophy, it means we have misunderstood at least some of Descartes's natural philosophy: his explanations in physiology (and perhaps elsewhere: see \$3.3). Where the explanations do not reduce to corpuscular mechanics, this is not a 'failure' on Descartes's part, but a property of the kind of explanation in use.

The focus of this paper is not on Descartes's own claims (in, e.g., the Principles) about what he is doing in natural philosophy: my intention is not to recover what Descartes really meant when he wrote about explanation. Instead, I am concerned with what Descartes actually does when he explains physiology. The ultimate concern of the paper lies with understanding the philosophical implications of Descartes's account of physiology rather than with understanding his intentions. Accordingly, I do not attempt to establish whether or not Descartes-the-philosopher would agree with my analysis of the work of Descartes-the-physiologist, and I use anachronism where 
avoiding it would be inefficient.

This is by no means to suggest that the analysis presented here is incompatible with Descartes's philosophy, however. For instance, while Descartes himself does not use the term 'system' in the sense employed here, a passage in La Forge's commentary on the I664 edition of Descartes's Traité de l'homme suggests that something like a systems reading was available in the period: the body-machine is 'composed of many organic parts which, united, work together to produce certain movements of which they would not be capable if they were separated'4 (La Forge I664: 173). Nor is my aim to describe a method for Descartes's physiology that is discontinuous with his larger project. I take it that aspects of systems explanations turn up throughout Descartes's natural philosophy $(\$ 3.3)$, and that the unity of the sciences is less at risk if we distinguish between explanatory and ontic systems, and rule out the latter (at least for now) $(\$ 2.2)$.

In what follows, \$2.I provides a definition of the type of system in question here, in the form of a brief outline of its structure; $\$ 2.2$ makes a distinction between explanatory and ontic systems, favouring the former for the purposes of this paper. The type of explanation outlined in $\$ 2$ is then used in $\$ 3$ to analyse Descartes's explanations of physiology. $\$ 3$.I focuses on his account of the heartbeat. First, \$3.I.I shows how the explanation is systemic and compositional. Next, \$3.I.2 demonstrates how Descartes's explanations are constructed in terms of the effects and components set out in \$2.I. The analysis of the explanation of the heartbeat concludes by showing that the components of the system exist at different explanatory levels (\$3.I.3). Systems explanations are not restricted to the heartbeat and associated systems, which $\$ 3.2$ demonstrates by applying the analysis to explanations of bodily growth and muscular movement, while $\$ 3.3$ assesses the extent which systems explanations, or some of their features, may be present outside the physiology.

${ }_{4}^{4}$. . . composé de plusieurs parties organiques qui estant unies, s’accordent à produire quelques mouvements, dont elles ne seroient pas capable, si elles etoient separées.' 


\section{Systems}

\section{I Definition}

I make use of systems explanations here as an analytical tool: the application of this analysis in the rest of the paper will show how it makes sense of Descartes's explanations of physiology.

An explanation is systemic insofar as it is given in terms of systems - that is, for the purposes of this paper, aggregations of components ${ }^{5}$, organised in such a way as to determine an effect. I refer to the organisation of the components as the system's 'composition', and it is the composition that is the ultimate determinant of the system's effect. ${ }^{6}$ The components are mostly systems themselves. When components are not systemic, they consist of nothing more than the behaviour of individual corpuscles (such as the stochastic movement of spirit-corpuscles in muscles). Non-systemic components are non-systemic because lower-level organisation plays no part in determining their behaviour. All components, both systemic and non-systemic, determine their own effects (e.g., a blood-expansion component determines the effect of blood expansion). As such, all components are activities rather than static (anatomical) structures: they are things that happen and, in doing so, determine other things to happen.

These explanations involve multiple levels when the components of the system exist at different levels: within the explanation, lower-level components have direct causal and dependency relations with higher-level components, and vice versa. The levels distinction relevant here is not

\footnotetext{
${ }_{5}$ Descartes uses the term 'part' ('partie' (AT xi: 225-6, 234, 253) or sometimes 'piece' (AT xi: II9)). I prefer 'component' here because of its connection to composition and because of its generality (we tend to think of parts as straightforwardly physical, whereas what constitutes a component depends on the system; here, components are activities).

${ }^{6}$ See Shapiro 2003 (435): '[w]hat makes a machine the machine it is . . is its particular composition'. And Gaukroger 2002 (393): 'Descartes wants to subordinate function to structure'. The notion of composition as presented in this paper might possibly, then, say something about the problem of function or 'office' (or even teleology) in Descartes's biology. On function in Descartes's physiology, see the excellent analysis in Brown 2orr. On teleology and related problems, in addition to Shapiro and Gaukroger, see Des Chene 200I (\$6.I, II7f.) and Simmons $200 \mathrm{I}$.
} 
between visible and subvisible (as in, e.g., Galison 1984) but between levels of organisation (the engine of a car is at a lower level than the car itself, but at a higher level than the pistons). There are multiple ways to hierarchise such levels, but doing so with precision is not necessary for the argument in this paper, which requires only a distinction between the lowest level and some higher level(s): where there are causal or dependency relations between any higher and any lower level, the system is multilevel.

\subsection{Explanatory versus ontic systems}

On the face of it, appeals to whole systems and multiple levels within them ought to be a serious problem for Descartes. His metaphysics commits him to an ontology of the natural world that cannot involve more than the shape, size and motion of pieces of extended substance. If he is invoking system properties and higher levels in preference to the behaviour of corpuscles, he appears to be in trouble. One way of dealing with this inconsistency would be to surmise that (A) Descartes's philosophical project is simply not as coherent as he wanted it to be. On reaching the outer branches of his tree of knowledge, perhaps he faltered, and perhaps things became somewhat messier than they had been within the solid roots of metaphysics. This is possible. ${ }^{7}$ On this reading, if Descartes does include systems of the kind described here in his physiology, they are ontic systems: they exist in the real, material world. In that case, he would be (presumably inadvertently) giving up on his ontological parsimony and tacitly accepting the existence of hearts and lungs as real entities in the world (or, rather, heart-beating and respiration as real activities in the world).

We can, however, find such systems in Descartes's physiology without breaking so radically from

\footnotetext{
${ }_{7}$ Machamer and McGuire (2009) suggest that inconsistency is the appropriate way to interpret the relation between Descartes's earlier and later work. They do not, however, uphold the kind of incoherence between Descartes's later metaphysics and physiology that (A) entails. I am grateful to an anonymous referee for pointing out the relevance of Machamer and McGuire here.
} 
his metaphysical commitments if (B) the systems are explanations only. ${ }^{8}$ On this reading, they are not ontic systems. Descartes does have ontic mechanisms, but they can exist only at the lowest level (i.e. the corpuscle level). Heart-beating, respiration, and blood-expansion get to be components of an explanatory system, but Cartesian ontic mechanisms are composed of corpuscle-behaviour alone. This means that, in a Cartesian world, systems with components on higher levels can never be isomorphic to ontic mechanisms. In addition, systems explanations cannot be direct descriptions of ontic mechanisms ${ }^{9}$, because systems include components that are not available to Cartesian ontic mechanisms. Because systems explanations cannot directly describe real-world mechanisms, the explanations may be hypothetical, or heuristic, or they may 'overlay' real-world mechanisms. ${ }^{\circ}$ My position is compatible with all three options. In the case of overlaying explanations, systems explanations would describe real-world mechanisms, but only indirectly, just because the components of the explanatory systems would bottom out at different levels from the components of the real-world mechanisms.

There is an argument to be made for (A), and the analysis in this paper would be broadly compatible with that position. Nevertheless, I have assumed (B) here, partly because it is the less revisionist path, and partly because it avoids problems that may be generated by conflating explanation with ontology (the paper remains agnostic about whether or not the explanatory systems overlay real-world mechanisms).

There might also be a case to be made for (C) an ontic reading of Cartesian systems that

\footnotetext{
${ }^{8}$ The 'how-possible' reading of Descartes's physiology given by Des Chene (2005) might lie somewhere between the incoherence and explanatory-systems readings. In the context of that interpretation, Descartes's how-possible explanations would be systemic rather than strictly reductionist.
}

\footnotetext{
9 Recent work on mechanism sees (modern) biological mechanistic explanation precisely as description of real-world mechanisms (Machamer et al. 2000: 3). It is a difference in ontology that allows for the difference in possibility of describing real-world mechanisms.
}

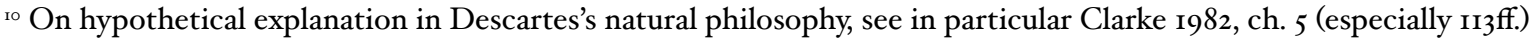
and Manning 2012.
} 
maintains the coherence of Descartes's project. While an ontic reading might seem entirely at odds with Descartes's ontology, perhaps allowing an ontological status to systems is not significantly more problematic than allowing it to corpuscles in a world of extended substance. ${ }^{\text {II }}$ This is potentially interesting, but making the case for it would be an undertaking lengthy enough to hijack the thesis of the present paper. Consequently, I leave (C) to be addressed elsewhere. If this paper is correct, however, and if (C) does indeed hold, then we will be able to say that Descartes's ontology contains real multilevel systems.

\section{Systems in Descartes's physiology}

\section{I The heartbeat}

The following section analyses Descartes's most extensive account of the heartbeat in terms of systems. The account comes from Descartes's Description of the Human Body (hereafter, Description), a late manuscript that integrates and expands on his prior work on physiology. The analysis shows that the explanation of the heartbeat involves considerably more than corpuscular mechanics (as defined in $\S_{I}$ ), first in terms of its systematicity and composition, then its effects and components, and finally its reliance on appeal to multiple explanatory levels.

\section{I.I Systematicity and composition}

For the purposes of this paper, a system is an aggregation of components, organised in such a way as to determine an effect $(\$ 2 . \mathrm{I})$. Consequently, if Descartes's explanations are given in terms of components whose organisation determines a particular effect, we can say that they are systemic. The second part of the Description is concerned with explaining the effect of the heartbeat (along with the effect of heat generation). While it begins with the movement of the heart itself, the complexity of the account escalates rapidly. It soon reaches the point where it is no longer limited to the activity of the heart alone. It extends inexorably first to the haematic circulatory system, then to the respiratory system, and then (in part three) to nutrition and assimilation (AT XI: 23If). The explanation of the heartbeat continues throughout: it is not that Descartes explains

\footnotetext{
II There might be some support for this position to be found in Descartes's remarks on the real distinction in the Principles (I/6o). Cf. Sowaal 2004.
} 
the heartbeat and then moves on to another physiological effect; rather, he explains the heartbeat by moving on. The explanation of the heartbeat requires the explanation of circulation, respiration, and so on. We see this in a nutshell when the explanation moves from the heart itself to circulation:

by these means [the blood in the arteries] swells and rises at the same time as the heart; and it is this movement, as much of the heart as of the arteries, that is called the pulse

(DHB: 5; AT xI: 232; my emphasis).

Clearly, Descartes does not see the heart and the circulatory system as independent entities. The movement of the pulse pertains as much to the heart as to the arteries. This implies that a change to the arteries, or to their relations with the heart, would mean a change in the movement that constitutes the heartbeat-effect. In other words, organisation (the composition of the system) must be playing a part in determining the effect here.

The case for the role of organisation grows stronger as the account continues. Descartes goes on to show how, just as the pulse depends on the heartbeat, the heartbeat depends on the pulse, via the circulation. This is because the reentry of the blood into the heart is a partial cause of the next heartbeat (see \$3.I.2). Thus, the heartbeat is dependent on circulation, and circulation is dependent on the heartbeat. Following the movement of blood through the circulation, the account naturally takes in the pulmonary blood vessels (AT xi: 235f.). And then it turns to the lungs, concluding that,

the main use of the lung consists in one thing alone: by means of the respiratory air, it thickens and tempers the blood that comes from the right ventricle of the heart before it enters the left ventricle; without this it would be too rare and too fine to serve to fuel the fire that it encounters there

(DHB: I77; AT xi: 236; my emphasis). 
The Description's account of the heartbeat does not - and seemingly cannot - keep these bodily systems isolated. As soon as the heartbeat is brought up, the circulation of the blood follows necessarily. And then respiration follows too. And it does not merely follow, because without the thickening of blood during respiration, there would be no heartbeat: respiration is indispensable for the process that explains the beating of the heart (and its warmth). It turns out that Descartes cannot give an account of the heartbeat without also referring to and relying on everything involved in respiration and circulation. Each plays a necessary role in explaining how the heartbeat works: in the absence of circulation or respiration, there would be no heartbeat. And each plays its role within a specific organisation: if respiration did not precede the entry of blood into the left ventricle, the blood would be 'too rare and too fine' for the process to continue; if circulation did not follow the active phase of the heartbeat, there would be no blood to re-enter the heart. Each must occur in a particular order for the heartbeat-effect to be produced.

The heartbeat, circulation, and respiration do not constitute, however, the extent of Descartes's explanation. The next section of the Description deals with the nutrition of the body's organs, which is a consequence of the circulation of the blood (AT xI: 245f.). But nutrition results in the loss of corpuscles from the blood (AT xI: 246). Thus, the explanation has to include assimilation as well. Otherwise, the supply of blood on which the heartbeat, circulation and nutrition depend would dry up. At the same time, assimilation depends on both the flow of blood provided by the heartbeat and circulation, and on the organ-integrity provided by nutrition. From the heartbeat, the circulation of the blood follows. And the nutrition of the organs follows the circulation. And assimilation follows nutrition. Simultaneously, each is dependent on the others. What started as an account of the heartbeat now encompasses the whole of the body. Each of the major parts of the body depends immediately on at least some of the others, which in turn depend on others, and on the original part in question. Ultimately, each part ends up depending on the whole system. At the same time, the system must depend on its component subsystems: 
in considering only the exterior of the human body, we never imagined that it had enough organs or springs in it to move itself in all the different ways in which we see it move

(DHB: I70; AT XI: 224).

Descartes's point is that, although they are not visible, the body does indeed (and must) contain all the organs and 'springs' it needs to operate. And when 'one of the principal parts of the body decays' (Passions a. 6; CSM I: 329; AT xi: 330), the whole body dies, and its systems cease to function. ${ }^{12}$ That is, the system of the body as a whole depends on its component subsystems, and their organisation, to such an extent that the failure of any one of them results in the failure of the whole.

The system of the principal parts of the body is thus not simply a chain of dependencies: it is not just the case that the heartbeat must follow respiration; respiration must also follow the heartbeat. Without the one, there would not be the other, and, crucially, vice versa. Most of all, it is the circularity that makes the dependencies here more than a simple chain. The movement of a billiard ball can be dependent on the movement of the ball that struck it, whose movement can in turn be dependent on the ball that struck it, and so on: that would constitute a chain. But a self-perpetuating system in which each component is simultaneously dependent on each of the others and on the system as a whole is a different matter. Descartes's explanation of the heartbeat looks like the latter rather than the former. As such, the dependencies are circular, and the system is intradependent: its subsystems are reciprocally dependent on each other. A failure in any one of them also results in the failure of each of the others (if the respiratory system stops working, the heart stops beating, and vice versa). And there is good reason to think that Descartes is quite aware of this, given that, after having established the dependencies between various functions involved, he describes the circulation and heartbeat as forming a 'perpetual circular motion' (DHB: I79; AT xI: 239): without the dependencies between functions, there

\footnotetext{
${ }^{12}$ Descartes does not list what he takes the principal parts to be, but, as the analysis here shows, they must include at least the heart and the circulatory, respiratory, and digestive systems - when any of those fails, the others cannot continue to work, and the body ceases to operate.
} 
would be no motion of the blood, and without the circularity of those dependencies, the motion would not be circular (blood would end up spraying out somewhere, and the body would die).

Brown (20II) recognises a similar interdependence of subsystems in Descartes's embryology, in which organs develop through accretion of particles deposited by a stream of fluid that flows along a circular path, such that 'the formation of the brain is necessary for the persistence of the heart and the formation of the heart a necessary precondition for the formation of the brain' (I2). Brown points out that what is special about the interdependence in Descartes's account of embryogenesis is that - unlike the metaphysical dependence of every piece of extended substance on every other piece - embryogenesis is not 'indifferent to the way in which matter is arranged' (I3). In other words, the organisation is integral in determining the effect: the interdependence of physiological subsystems makes for a strong form of systematicity. What we see when we look at the account of the heartbeat is that interdependence goes beyond development. For Descartes, the parts of the living body are in a continuous and perpetual state of interdependence, and the body itself is therefore strongly systematic for as long as it is alive.

The interdependence here is a strong case; it is not the sole determiner of systematicity. For some of the body's subsystems, the dependency is clearly one-way: muscular movement or hearing both depend on the whole body, but not vice versa. Aside from the possibility of internal interdependence in muscular movement and hearing systems, these cases still fulfil the minimum condition for systematicity given in \$2.I (a particular organisation of components (of some kind) that determines a particular effect).

So far, everything in the explanation has taken place at a high level (heartbeat, circulation, respiration, etc.); the following section moves the analysis to a lower level of organisation: what, on Descartes's account, happens inside the heart. It finds the components involved in the explanation, and shows how, through their organisation, they determine the effects of the system. 


\subsubsection{Effects, components and activities}

Systems, like bodies, are made up of parts, which I refer to here as 'components'. The obvious place to look for the components of Descartes's physiological systems is in the anatomical structures of the body: hearts and lungs and so on. However, in what follows, I argue that we can make better sense of Descartes's systemic explanations if we do not take the components to be anatomical. On the reading presented here, the components are activities instead: heart-beating and respiration, rather than hearts and lungs. We saw an instance of this in the last section, in Descartes's recognition that the pulse is a movement continuous throughout various anatomical structures, and not localisable to any particular one. The activities that Descartes invokes are often motions (colliding, falling, etc.), but they need not be: they could also be, e.g., resistance, or tendency to motion.

The main section of the Description, titled 'on the motion of the heart and blood', does begin with anatomy. Here, though, anatomy is only background knowledge for the explanation of the heartbeat and circulation. As such, it is necessary both for constructing and for understanding the explanation, but it is not part of the explanation itself. The introduction to the Description claims that the text requires only minimal knowledge of anatomy, and that anything beyond the very basics will be introduced when necessary (AT xI: 226). Echoing the earlier Discourse (AT vi: 47), Descartes asks the reader to obtain and dissect 'the heart of some land animal, something reasonably large (for they are more or less similar to those of men)'. We are then expected to follow along with the dissection while he briefly describes the heart's gross anatomy (DHB: I724; AT XI: 228-3I). That this is background knowledge is made explicit when Descartes segues into the explanation proper:

When the anatomy of the heart is seen in this way, if one considers that it always has more heat in it when the animal is alive than any other part of the body, and that the blood is of such a nature that when it is a little hotter than usual it expands very quickly, one cannot doubt that the movement of the heart, and following it the pulse, or the beating of the arteries, occurs in the way that I shall describe

(DHB: 174; AT xI: 231; my emphasis). 
Descartes lists three items of knowledge necessary for his explanation but not part of it: cardiac anatomy, the heart's greater warmth relative to the rest of the body, and the propensity of blood to expand at low temperatures. (We should presumably add the principles of his physics as a tacit fourth.) His point here is that, in light of these three items, the heartbeat and circulation must work in just the way he is about to describe. This implies two things: that the explanation is yet to begin, and that anatomy is not a component of the explanation-i.e. that it is background knowledge.

At first sight, it seems surprising that the anatomy of the heart should not play a role in an explanation of the heartbeat. But (per \$2.I), components are activities. And seeing components as activities makes sense of Descartes's treatment of anatomy: a dissected heart is inactive - or 'deflated (as it always is when animals are dead)' (DHB: I73; AT xI: 229) - and the features of an inactive heart do not themselves explain the active beating of the heart. ${ }^{13}$ Consequently, the anatomical features of the heart are not components in Descartes's explanatory system. It is only when Descartes begins to describe a system of active components (making use of the background knowledge of anatomy) that he begins to explain the heartbeat (and the circulation). This much is consistent with his explanations of physical phenomena outside of physiology: it is the tendency to motion of particles that carries the weight in explaining light propagation, for instance, rather than the particles themselves. In the terms of this paper, tendency to motion would constitute an activity.

The explanation proceeds as follows:

[w] hen the heart is elongated and deflated, there is no blood in its ventricles, except for a small amount which remains from that which has previously been rarefied. This is why two large drops enter them there, one falling from the vena cava into its right ventricle, and the other falling from the pulmonary vein into the left one,

\footnotetext{
${ }^{13} \mathrm{~A}$ dissected heart is not necessarily inactive for Descartes. In his correspondence with Plempius, he cites two experiments on fish hearts 'which, after they have been cut out, go on beating...' (CSMK: 80; AT I: 523). In this case, although dissected, they are still active hearts. It is still the activity that is relevant. See to Plempius, 15 February ${ }_{16} 63$ (AT I: 523) and 23 March i638 (AT iI: 66f.).
} 
and the small amount of rarefied blood that remains in these ventricles, mixing straightaway with the fresh blood coming in, is like a kind of yeast, which causes it to beat and expand immediately, and by these means the heart swells, hardens, and becomes a little squatter in shape ...

(DHB: 174; AT xI: 23I; my emphases).

This short passage alone makes use of activities of elongation, deflation, remaining, rarefaction, entering, falling, mixing, causing, heating, expanding, swelling, hardening and becoming 'a little squatter in shape'. These are the components in the account. They are what Descartes uses to construct the explanation. Drops of blood enter and fall into the ventricles. There, they mix with previously rarefied blood, which acts 'like a kind of yeast [levain]'. This causes the new blood to heat up and expand. As a result, the heart 'swells, hardens, and becomes a little squatter in shape'. At the same time, the membranes between the vena cava and the right ventricle, and between the pulmonary vein and the left ventricle are forced closed (like valves). This prevents the blood from exiting the ventricle the way it entered. Instead, it escapes through the pulmonary artery and the aorta, from the right and left ventricles respectively (AT xI: 232).

Anatomy in itself is not directly explanatory within the account, but it is not entirely absent either. Where it is invoked, it is subordinated to the activity. The vena cava comes into the explanation only as the place from which blood enters. Similarly, the ventricles are the place where new blood falls and mixes with the rarefied blood, and where that rarefied blood has remained after the active phase of the heartbeat. The ventricles are also present in the account via the constraining activity that conspires with the rarefaction of the blood to determine its exit through the arteries (AT XI: 232). In the same way, the blood is not portrayed here as simply a fluid being pumped through the heart. It is active throughout the account. The falling of fresh blood into the heart and its mixing with the remaining rarefied blood (partly) determines its expansion. And the expansion itself is, for Descartes, the activity that inflates the heart. Even the rarefied blood that remains in the ventricles does not sit there passively: Descartes explicitly describes it in active terms: as causing the fresh blood to expand when they mix. 
So, the components in the explanation are activities. And it is their activity that gives them their explanatory power: the heart's deflating does something, and what it does contributes to what the whole system does. But, that is not to say that the activity of the system reduces down to what its components do. Any component isolated from the system's composition would contribute nothing to the activity of the system. It is the composition, and not the constituent components, that determines the system's effect. Thus, rarefying blood would simply expand uselessly if it were not within a ventricle too small to keep it contained, with valves that open to let it flow out, etc. But, when rarefying blood is taken along with heart deflation and the other components of the system, in the right composition, we get the heartbeat.

So far, the components involved in the explanation have all been at a fairly high level. Even an activity as simple as the falling of blood is at a clearly higher level than corpuscles (since talk about blood behaviour is not talk about corpuscle behaviour). As it stands, the explanation is clearly not a reduction all the way down to corpuscular mechanics: corpuscles have not even entered into it at this point. We still need to establish whether the explanation ever reaches down to corpuscles. The next section looks at a corpuscle-level account of blood expansion in the heart, and then shows how Descartes has to integrate it with plainly higher-level components in order to construct an explanation of the heartbeat.

\section{I.3 Multilevel explanation}

The section of the Description that deals with the motion of the heart and blood provides no explanation of the initial cause of the blood's expansion. What it does offer is an analogy in which the blood acts like yeast (AT xI: 23I). But it does not explain the mechanism that causes the yeast-like activity. For that explanation, we need to look at an account later in the Description, in the section on embryogenesis:

when most of the blood leaves the heart at the time of diastole, those of its particles which remain there enter into the flesh, where they find pores disposed in such a way, and fibres agitated in such a way, that there is only matter of the first element surrounding them; and at systole these pores change shape because 
the heart lengthens, which makes the particles of blood, which remained there as if they were to serve as yeast, leave there with a great speed, and in this way entering easily into the new blood coming into the heart, they make its particles separate from one another, and in separating thus they acquire the form of fire

(DHB: 203; AT xI: 28If.; translation adjusted).

The yeast allusion reappears in this passage, but this time gets accounted for down to the corpuscle (particle) level. In this case, the 'yeast' activity is explained by the ejection of corpuscles of blood from pores in the heart wall. These corpuscles hit the new blood concurrently entering the heart. The yeast-acting blood corpuscles move at such speed that collision with the corpuscles of the new blood makes the latter move significantly further and faster. The result of this is that the blood both heats up and expands. As in the account covered in \$3.I.2, once the blood has expanded and most of it has forced its way into the arteries under its own pressure, a small amount remains in the ventricles. Descartes now specifies that what remains sinks into pores in the heart wall. The rarefied blood stays there until the heart enters systole (its passive phase for Descartes) and relaxes. In relaxing, the heart lengthens, compressing its walls relative to their state when the heart was 'a little squatter' during diastole. This compression of the walls is also a compression of the pores within them. The result of this is to force the yeast-acting blood out into the new blood that is in the process of entering. At this point, the active phase begins again, and the whole process of the heartbeat repeats.

A fairly obvious objection arises at this point. Since the passage above shows that Descartes has an explanation of blood expansion in terms of corpuscles, perhaps the account of the heartbeat might simply be straightforward Cartesian reduction to corpuscular mechanics, and not a multilevel system after all. However, this relies on mistaking a (partial) appeal to the behaviour of corpuscles for a full reduction of the phenomenon to the corpuscular level. In the account above, corpuscles are invoked for only part of the explanation. There are three components at the corpuscular level: (I) blood corpuscles moving at high speed, (2) blood corpuscle collisions and (3) increased mean blood corpuscle movement as a result of (2). (There are also the corpuscles of the first element (the smallest of Descartes's three elements), although their role is fairly obscure in 
this particular account. ${ }^{\mathrm{I}}$ ) At most, this can count as a reduction of blood heating (and, indirectly, blood expansion, because increased mean blood corpuscle movement leads to expansion as well as heat) to the corpuscular level. But the effect in question is the heartbeat, and the corpuscle level here certainly does not provide enough to explain how the heart beats. ${ }^{15}$

Given that the blood-corpuscle behaviour alone is not enough to explain the heartbeat-effect, we need to consider the other components Descartes invokes in the account above. If we look at what he actually appeals to, rather than concentrating on the corpuscles, we see a rather different picture of explanation from the corpuscular-mechanics approach. The corpuscle-talk is integrated with appeals to higher levels throughout. The remaining blood corpuscles enter into the 'flesh' of the heart, which is (at least partially) described in terms of pores and fibres. Pores and fibres are not corpuscle-level descriptions. They presumably could be reduced to corpuscles, in principle. But that is not the level to which Descartes appeals here: the interaction of blood corpuscles with the heart wall is not explained in terms of corpuscular mechanics. Most notably, the movement of the yeast-acting blood corpuscles in the account is caused by the relaxation/ lengthening of the heart (via the resultant contraction of the pores). If the heartbeat-effect is the highest level in this explanation, and the blood corpuscles the lowest, then heart-lengthening is surely somewhere in between (and presumably closer to the top). So, it is the speed of the movement of the yeast-acting blood corpuscles that allows them to impart movement to the corpuscles of new blood and thus cause heating and expansion. But, it is the higher-level lengthening of the heart that causes the movement of the yeast-acting corpuscles. As such, the explanation is incomplete if it is left at the corpuscle level: the corpuscle-level activity is explained by means of a higher-level activity.

\footnotetext{
${ }^{\text {i4 }}$ There are strong parallels between this account and the explanation of fermentation in damp hay in Principles 4:92. There, corpuscles of the first element accelerate corpuscles of grass sap, ultimately causing heat, under certain conditions. Similarly, a little earlier in the Description, Descartes discusses the origin of heat in the developing foetus in terms of matter of the second element agitated by matter of the first (AT XI: 28I).
}

\footnotetext{
${ }^{\text {Is }}$ In the Rules, Descartes characterises reduction as comprising both an analytic and a synthetic step (AT x: $379^{-87}$ ). What can be synthesised from the terms in use here (the corpuscle behaviour) is blood heating/expansion rather than the heartbeat.
} 
In fact, the explanation is still not complete even with the integration of blood corpuscle behaviour and heart-lengthening. It is incomplete because it does not yet explain the heartbeat effect. An explanation of the heartbeat that goes down to the corpuscle level will need to integrate (I) the account discussed in this section of this paper with (2) the higher-level explanation discussed in the previous two sections. (I) explicitly explains only the production of heat in the heart. Implicitly, it also explains blood expansion. But it does not explain the heartbeat. Explaining the effect requires appealing to (at least) the following features of (2): the swelling of the heart, the restriction of space for the expanding blood in the ventricles, the valve operation at the entrance and exit blood vessels, circulation and respiration (and probably also nutrition and assimilation). Thus, the account does not explain the heartbeat without appealing to multiple levels. The corpuscle level is required to explain the expansion of the blood-but the explanation requires appealing to the higher-level interactions with the pores and fibres of the heart wall and (especially) to the higher-level lengthening of the heart. At the same time, higher levels explain the swelling of the heart, and the restriction that causes it and forces the blood out. But they do so only alongside the explanation of blood expansion. All these levels are necessary for the account to explain the heartbeat.

The natural objection now is to point out that, in principle, the whole account could be translated into the corpuscular level, even if Descartes chose not to. The problem with this is that it conflates explanatory reduction with ontological reduction. In principle, Descartes ought to be able to reduce the relaxation and lengthening of the heart to corpuscular mechanics, given his metaphysics (i.e. the physical world is nothing but extended substance differentiated by movement). That is, ontological reduction should always be a possibility in the Cartesian world. But, when the goal is an explanation of the heartbeat, a description of heart-lengthening in terms of corpuscles would just miss the point. The question here is one of relevance to the explanation. In other words, it is a question of what plays an explanatory role. Heart-lengthening is necessary for explaining the movement of the yeast-acting blood corpuscles. As such, it plays an explanatory role. Now, heart-lengthening could indeed be reduced to the corpuscle level. Doing so would require an account of the structure, behaviour and interactions of the corpuscles that make up the heart wall. It would also require a similar account of the corpuscles that make up any other parts of the heart's anatomy that move when the heart lengthens, since they would all 
be involved in corpuscle-to-corpuscle interactions in the process of heart-lengthening. Because this would be a corpuscle-level explanation (and thus non-systemic), we would not need to account for every single corpuscle. But we would need to account for every corpuscle behaviour that, in aggregate, composes heart-lengthening.

If Descartes's aim were to explain heart-lengthening itself, or some other higher-level elastic effect, the corpuscle-talk might fulfil an explanatory role. But given that the aim is to explain the heartbeat, it is not at all clear that anything would be gained by invoking low-level corpuscle behaviour in preference to high-level heart-lengthening. Worse, doing so risks obscuring the relevant component of the explanatory system (heart-lengthening) beneath the profusion of corpuscle talk. The situation is analogous to attempting to explain the operation of a mechanical clock by appealing to the interactions of the molecules, atoms, or subatomic particles (or, for that matter, corpuscles) that make up the material of the cogs: if you were to ask me how a clock works, and I were to respond by talking about quantum probability clouds, you would rightly accuse me of answering a different question. My response would have been, intuitively, below a relevance threshold for an explanation of the operation of a clock. In the same way, for Descartes to reduce heart-lengthening to the corpuscle level would be to answer a different question from that of how the heartbeat works. It is in this sense that higher-level heart-lengthening is relevant to the explanation while the corpuscle behaviour is not. ${ }^{16}$ Even if Descartes may claim elsewhere that explanation should be in terms of corpuscular mechanics, when he explains the heartbeat, he pays attention to a relevance threshold. As such, he selects components from different levels, on the basis of their relevance to the explanation.

Another version of this objection might be to point out that the heart (along with everything else in the material world for Descartes) originally developed from nothing more than the activity of individual corpuscles. That is, that whatever complex systems might exist in living bodies were ultimately formed by corpuscles knocking into each other. But, similarly, an account of the development of the heart would be an answer to a different question: 'where did the heart

\footnotetext{
${ }^{16}$ My point here is similar to the discussion of bottoming-out in \$5.I of Machamer et al. 2000: '[b]ottoming out is relative ... The explanation comes to an end, and description of lower-level mechanisms would be irrelevant' (I3).
} 
come from?', rather than 'how does the heart work?'. If Descartes started to explain how the heart works by appealing to corpuscle collisions in his cosmological vortices, we would justifiably accuse him of missing the point of the question.

There is good evidence, then, for concluding that Descartes does appeal to multiple levels in his explanation of the heartbeat. He appeals to the higher-level activity of heart-lengthening, for example, when he discusses the production of heat and the expansion of blood in terms of (lowlevel) corpuscular mechanics. But there are also good reasons to go further and claim that multilevelness in systems provides Descartes with better explanations (in at least some circumstances in physiology) than the strict reduction he is supposed to employ. That is, strict adherence to single-level reduction would obscure the higher-level components that play central roles in the explanation. Thus, Descartes's strategy is not to pursue reduction down to lowestlevel explanation. Instead, he picks and chooses the more relevant components for his explanatory system from amongst multiple explanatory levels.

\subsection{More systems: muscular movement and nutrition}

The Description's explanation of the heartbeat and circulation is not the only system in Descartes's physiology. We can see the same structure of explanation in the account of muscular movement in The Passions. The account appeals to the corpuscles that make up the animal spirits. But the spirit corpuscles are only components in a larger explanatory system. On this account, a muscle contracts and lengthens because it contains a large quantity of very small corpuscles which move 'very quickly, sometimes merely eddying in the place where they are located ..., and sometimes flowing into the opposed muscle' (a. II; CSM I: 332; AT xI: 366). The spirit corpuscles move in much the same way as the corpuscles of rarefied blood in the account of the heartbeat. Through this movement, the muscle containing the spirit corpuscles becomes swollen. As a result of the swelling, it contracts, and thus pulls, giving us muscular movement. But the behaviour of individual particles alone does not determine the movement of the muscle. In addition, the explanation of muscular movement requires appeal to the following higher-level components: the space restriction of the muscle itself (in the same way as the heartbeat requires the space restriction of the ventricles), the opposition of a pair of muscles, and some means to 
control which muscle contains the majority of the spirits (Passions a. II). It is this entire system, with its particular composition, that forms the explanation of muscular movement.

We can find similar use of systems explanation in the much earlier Treatise on Man (written I6323). Its explanation of nutrition is one such case. It appeals to the collision of blood corpuscles with the 'roots' of organs, which originate from 'the extremities of the little branches' of the arteries. As the blood flows through the arteries, the pressure of the pulse following the active phase of the heartbeat forces some blood corpuscles into contact with the organ roots. The blood corpuscles push the organ root corpuscles 'in front of them a little, and in this way gradually replace them'. But this alone is not what causes nutrition for Descartes. You get nutrition when new blood corpuscles are left attached to organ roots. And this is explained by appeal to a higher-level component: 'at the moment when the arteries deflate, each of these parts is stopped in its place, and this alone means it is joined to those it touches' (TM: IO3; AT XI: I26). Higher-level artery deflation is what causes blood corpuscles to remain attached to the organ roots with which they had collided, and thus to provide them with nutrition. In this case, the activity of the corpuscles is necessary to explain nutrition. But it is not sufficient for the explanation, because the system also requires appeal to artery deflation, on a higher explanatory level, within the context of a composition that determines the effect of nutrition. As such, this explanation too consists not of corpuscle behaviour alone but of a composed system comprising components on separate levels, with explanatory appeals made between levels.

Of course, Descartes also gives some accounts that straightforwardly seem to keep to a single explanatory level-Man's treatment of digestion, for instance (AT XI: I2I). This is to be expected: sometimes the relevancy criterion bottoms and tops out at the corpuscle level, and some effects may be explicable in terms of corpuscle behaviour alone, without the latter's being placed within the context of a system. However, as the previous sections have shown, corpuscular mechanics is far from being the only means of explanation in Descartes's physiology: it is in terms of systems that Descartes explains (amongst other things) what he takes to be the most central function of the body - the heartbeat - where most is at stake (AT xI: 245). 


\subsection{Systems beyond physiology ${ }^{17}$}

So far, this paper has maintained a simplified distinction between Descartes's explanations in physiology and his explanations elsewhere: physiology involves systems, while corpuscular mechanics suffices for physics. In truth, that distinction is not quite so straightforward. Descartes's cosmological vortices certainly look like complex systems. In his optics, he appeals to higher levels alongside corpuscles: reflection and refraction are explained through the motion of balls (analogous to corpuscles, i.e. low-level) thrown, respectively, against the ground and into water (both higher-level) (AT vi: 93-IOI). I have focused on physiology here because physiology seems to be where the disparity between corpuscular mechanics and the explanations Descartes actually uses is the most noticeable.

But that is not to say that systems explanations, or some features of systems explanation, are not present elsewhere in Descartes's natural philosophy. At the very least, I suspect Descartes frequently finds that appealing to higher levels produces better (i.e. more explanatorily relevant) explanations throughout natural philosophy than could be provided by pure corpuscular mechanics. He may well find the same for systematicity in some cases, although perhaps to a more limited degree than in physiology. The account of vortices, for example, would probably be closer to what Haugeland (1978: 216) calls a 'morphological explanation', in which the effect is the product of the aggregate activity of many parts but is indifferent to their organisation: if you completely rearrange the parts of a vortex, you still have a functioning vortex; the same cannot be said of a living body. Regardless, to whatever extent Descartes's explanations elsewhere look like the systems discussed here, the conclusions of this paper will be (partially) applicable throughout his natural philosophy.

\section{Conclusion}

Descartes is generally taken to be a strict explanatory reductionist about the natural world. His metaphysical commitments seem to tie him to explanation in terms of corpuscular mechanics:

\footnotetext{
${ }^{17}$ I am grateful to an anonymous reviewer both for raising the concerns addressed in the following section and for suggesting relevant examples.
} 
his aim appears to be the reduction of complex observable phenomena to nothing more than the particular behaviour of individual subvisible corpuscles taken in isolation. However, at least some of Descartes's explanations in physiology (and perhaps elsewhere) look nothing like explanations in terms of corpuscular mechanics. Instead, they are systemic, and they appeal to multiple explanatory levels. In these systems, the effects are not determined by the behaviour of individual corpuscles. They are determined by the composition of the whole system. And the components of that system are drawn from different levels, with interlevel causation and dependency relations.

The analysis offered here shows that we misunderstand Descartes's natural philosophy if, as the standard view has it, we take him to pursue reduction to the lowest level in order to provide explanations. It is not only that he does not in fact reduce what he takes to be the principal physiological systems to corpuscular mechanics. Systems explanations are better explanations in some cases, where it is the entire composition that explains the effect (rather than the behaviour of individual corpuscles), and where each component is taken from the level that is explanatorily relevant for that component. Thus, the explanatory power of Descartes's physiology comes not from its reductionism as such, but from its willingness to stop the reduction where appropriate..$^{18}$

\footnotetext{
${ }^{18}$ Thanks to my colleagues at Ghent, and in particular to Eric Schliesser, Laura Georgescu and two excellent anonymous referees for extremely helpful comments.
} 


\section{References}

\section{Works by Descartes}

(CSM I) Descartes, R. (1985) The philosophical writings of Descartes, eds \& trans J. Cottingham, R. Stoothoff and D. Murdoch, vol I, ist edn. Cambridge: Cambridge University Press.

(CSMK) Descartes, R. (I99I) The philosophical writings of Descartes: The correspondence, eds \& trans J. Cottingham, R. Stoothoff and D. Murdoch and A. Kenny, Ist ed. Cambridge: Cambridge University Press.

(AT) Descartes, R. (1996) Oeuvres de Descartes, eds C. Adam, P. Tannery. II vols, I996 edn. Paris: J Vrin.

(TM) Descartes, R. (1998) The treatise on man, in S. Gaukroger (ed. \& trans.) Descartes: The World and other writings, 99-169. Cambridge: Cambridge University Press.

(DHB) Descartes, R. (1998) The description of the human body, in S. Gaukroger (ed. \& trans.) Descartes: The World and other writings, 170-205. Cambridge: Cambridge University Press.

\section{Works by others}

Brown, D. (201I) 'Cartesian functional analysis', Australasian fournal of Philosophy, 90/1: 75-92. doi: I0.IO80/00048402.20II.566274.

Buchwald, J.Z. (2008) 'Descartes's experimental journey past the prism and through the invisible world to the rainbow', Annals of Science, 65/I: I-46.

Clarke, D. (1982) Descartes'philosophy of science, ist edn. Manchester: Manchester University Press.

Des Chene, D. (200I) Spirits \& clocks: Machine \& organism in Descartes, Ist edn. Ithaca, NY: Cornell University Press.

Des Chene, D. (2005) 'Mechanisms of life in the seventeenth century: Borelli, Perrault, Régis', Studies in History and Philosophy of Science Part C, 36 (2): 245-60. doi: IO.IOI6/j.shpsc.2005.03.002

Fuchs, T. (200I) The mechanization of the heart: Harvey and Descartes, trans. M. Grene, Ist edn. Rochester, NY: University of Rochester Press.

Galison, P. (I984) 'Descartes's comparisons: From the invisible to the visible', Isis, 75/2: 31 $\mathrm{II}^{-26}$.

Garber, D. (2001a) 'Descartes and method in I637', in D. Garber Descartes Embodied, 33-51. Cambridge: Cambridge University Press.

Garber, D. (200Ib) 'Descartes and experiment in the Discourse and Essays', in D. Garber Descartes Embodied, 85-IIO. Cambridge: Cambridge University Press. 
Garber, D. (200Ic) 'Descartes on knowledge and certainty', in D. Garber Descartes Embodied, III29. Cambridge: Cambridge University Press.

Gaukroger, S. (2002) Descartes'system of natural philosophy, ist edn. Cambridge: Cambridge University Press.

Georgescu, L. and M. Giurgea 20I2. 'Redefining the role of experiment in Bacon's natural history: How Baconian was Descartes before emerging from his cocoon?', Early Science and Medicine, $\mathrm{I} 7 / \mathrm{I}-2:$ 158-80. doi: IO.II63/1573382I2X631828.

Haugeland, J. (1978) 'The nature and plausibility of cognitivism', The Behavioral and Brain Sciences, 2: $215^{-60}$.

Hatfield, G. (1992) 'Descartes' physiology and its relation to his psychology', in J. Cottingham (ed.) The Cambridge Companion to Descartes, 335-70. Cambridge: Cambridge University Press.

Hatfield, Gary (2002) 'Descartes' naturalism about the mental', in S. Gaukroger, J. Schuster and J. Sutton (eds) Descartes' Natural Philosophy, 630-58. London: Routledge.

La Forge, L. (1664) 'Remarques de Louis de La Forge, Docteur en médecine, sur le Traitté de l'homme, de René Descartes; et sur les figures par luy inventées', in R. Descartes L'Homme de René Descartes et un traitté de la formation du foetus du mesme autheur, $\mathrm{I}_{7}{ }^{-} 408$. Paris: C. Angot.

Machamer, P., L. Darden and C. Craver (2000) 'Thinking about mechanisms', Philosophy of Science, 67/I: I-25.

Machamer, P. and J. E. McGuire (2009) Descartes's Changing Mind, ist edn. Princeton: Princeton University Press.

Manning, G. (2012) 'Analogy and falsification in Descartes' physics', Studies in the History and Philosophy of Science Part A, 43: 402-II. doi:IO.IOI6/ j.shpsa.2012.02.003.

Shapiro, L. (2003) 'The health of the body-machine? Or seventeenth century mechanism and the concept of health', Perspectives on Science II/4: 42I-42.

Simmons, A. (200I) 'Sensible ends: Latent teleology in Descartes' account of sensation', fournal of the History of Philosophy 39/I: 49-75.

Smith, J. (2006a) Introduction, in J. Smith (ed.) The problem of animal generation in early modern philosophy, ${ }^{-}-20$. Cambridge: Cambridge University Press.

Smith, J. (2006b) 'Imagination and the problem of heredity in mechanist embryology', in J. Smith

(ed.) The problem of animal generation in early modern philosophy, 80-

I02. Cambridge: Cambridge University Press. 
Please cite version published in The Philosophical 2uarterly 65/26I (2015): 669-689.

Sowaal, A. (2004) 'Cartesian bodies', Canadian fournal of Philosophy, 34/2: 217-40.

Theurer, K (2013) 'Seventeenth-century mechanism: An alternative framework for reductionism', Philosophy of Science, 80/5: 907-18.

Ghent University, Belgium 